\title{
Assessment of inbreeding depression in a Guzerat dairy herd: Effects of individual increase in inbreeding coefficients on production and reproduction
}

\author{
J. C. C. Panetto, ${ }^{* 1}$ J. P. Gutiérrez,† J. B. S. Ferraz,† D. G. Cunha, ${ }^{*}$ and B. L. Golden§ \\ ${ }^{*}$ Curso de Veterinária, Universidade de Uberaba, Av. Nenê Sabino, 1801, 38050-501, Uberaba, MG, Brazil \\ †Departamento de Producción Animal, Faculdad de Veterinaria, Universidad Complutense de Madrid, Avda. Puerta de Hierro s/n, 28040 Madrid, \\ Spain \\ †Faculdade de Zootecnia e Engenharia de Alimentos, Universidade de São Paulo, Cx. P. 23, 13635-900, Pirassununga, SP, Brazil \\ §Dairy Science Department, California Polytechnic State University, San Luis Obispo 93407-0257
}

\section{ABSTRACT}

Influences of inbreeding on daily milk yield (DMY), age at first calving (AFC), and calving intervals (CI) were determined on a highly inbred zebu dairy subpopulation of the Guzerat breed. Variance components were estimated using animal models in single-trait analyses. Two approaches were employed to estimate inbreeding depression: using individual increase in inbreeding coefficients or using inbreeding coefficients as possible covariates included in the statistical models. The pedigree file included 9,915 animals, of which 9,055 were inbred, with an average inbreeding coefficient of $15.2 \%$. The maximum inbreeding coefficient observed was $49.45 \%$, and the average inbreeding for the females still in the herd during the analysis was $26.42 \%$. Heritability estimates were 0.27 for DMY and 0.38 for AFC. The genetic variance ratio estimated with the random regression model for CI ranged around 0.10. Increased inbreeding caused poorer performance in DMY, AFC, and CI. However, some of the cows with the highest milk yield were among the highly inbred animals in this subpopulation. Individual increase in inbreeding used as a covariate in the statistical models accounted for inbreeding depression while avoiding overestimation that may result when fitting inbreeding coefficients.

Key words: Guzerat, inbreeding, production, reproduction

\section{INTRODUCTION}

Evaluation techniques based on BLUP procedures have increased the accuracy of selection and hence contributed to better responses to selection. Simultaneously, artificial reproductive technologies have allowed increased selection intensities by reducing the number of selected animals necessary to produce subsequent

Received February 23, 2010.

Accepted June 10, 2010.

${ }^{1}$ Corresponding author: jcpanetto@hotmail.com generations and reducing generation intervals by increasing the number of possible progeny obtained from young breeding animals. For example, Peixoto et al. (2006) investigated the potential of producing sires of high genetic merit for improvement of milk yield using multiple ovulation and embryo transfer nucleus applied to Guzerat dairy herds in Brazil.

On the other hand, intensive use of small numbers of sires and dams can lead to increased inbreeding and reduced genetic variability within and among livestock populations. Decreased performance in traits related to production, reproduction, and health in dairy cattle have been reported by many authors to be caused by inbreeding (Hudson and Van Vleck, 1984; Smith et al., 1998; González-Recio et al., 2007; Mc Parland et al., 2007; Maiwashe et al., 2008). This reduced mean phenotypic performance is called inbreeding depression (Falconer, 1981). Zebu breeds in Brazil have tended to lose genetic variability because of their small numbers of founders and applied selection practices. This was observed by Faria et al. (2009), who realized that inbreeding levels on Nelore, Gyr, and Guzerat registered herds in Brazil had been increasing with time. Those authors have also pointed out the need for additional investigation into the possible consequences of inbreeding for these breeds.

Nevertheless, if selection and inbreeding are applied simultaneously, deleterious alleles can possibly have their frequency diminished in the population. Thus, individuals who accumulated inbreeding over a large number of generations would be expected to show less inbreeding depression because selection would have had more chances to purge deleterious genes (Gulisija et al., 2007; Van Wyk et al., 2009).

Another aspect to be considered is that increase in the traditional inbreeding coefficient $\left(F_{i}\right.$; Wright, 1931) is not linear across generations and may lead to different conclusions concerning inbreeding depression depending on the pedigree depth, as noted by Smith et al. (1998), Cassell et al. (2003), and González-Recio et al. (2007). An alternative measure of inbreeding, 
called the individual increase in inbreeding $\left(\Delta F_{i}\right)$, was proposed by González-Recio et al. (2007) and modified by Gutiérrez et al. (2009) to take into consideration an adjustment for the depth of the known pedigree for each animal.

The objective of the present study was to determine the influence of inbreeding on daily milk yield (DMY), age at first calving (AFC), and calving interval (CI) of females from a highly inbred elite zebu dairy herd of the Guzerat breed. Individual increase in inbreeding coefficients was included in the statistical models as an alternative to the usual individual inbreeding coefficients in order to access inbreeding depression to determine whether the 2 methods yielded different conclusions about the effects of inbreeding.

\section{MATERIALS AND METHODS}

\section{Data and Population Structure}

Records from an elite zebu subpopulation of dairy Guzerat cattle were used in the present study. This subpopulation comprised only 1 herd from 1895 until 1956. From 1957 until 1979 the subpopulation was divided into 2 different herds, both in the Rio de Janeiro State, Brazil. From 1980 to 2004 it was consolidated to just 1 herd again. In 2005 the subpopulation was divided into 2 different herds, one in the state of Rio de Janeiro and another in the state of Minas Gerais, Brazil. Calving dates and milk yields were recorded beginning in 1895 and were still being recorded when the analyses for the present study was performed in 2009 . The initial herd began with a small number of animals imported from India to Brazil in the period between the late nineteenth and early twentieth centuries. The herd was closed after those initial importations of cattle and the subpopulation has been bred without any further introduction of external genetics. This subpopulation has been an important source of seedstock to many Guzerat or crossbred dairy herds in Brazil and other tropical countries and has been previously studied by Paneto et al. (2008).

At the end of the 1970s a major reduction in the number of active breeding animals occurred in this subpopulation because of economic limitations. The reduced number persisted until the late 1990s and then the number of animals was increased by increasingly intensive use of in vitro fertilization (IVF) and embryo transfer. When the current analysis was performed the subpopulation consisted of 682 living animals, including cows, heifers, calves, and bulls. As a consequence of being closed and having a small number of founders, among the 9,915 animals in the pedigree file, $91.3 \%$ $(9,055)$ had a nonzero inbreeding coefficient.
Traits analyzed included DMY, AFC, and CI. Total lactation records were estimated based on monthly measurements. Cows were milked twice each day. Lactations averaged $285 \mathrm{~d}$, with a minimum of $143 \mathrm{~d}$ and a maximum of $461 \mathrm{~d}$. When longer than $305 \mathrm{~d}$, lactation milk yields have been adjusted to a $305-d$ period. Estimated lactation yields were divided by 305 to obtain values of DMY.

During the data space of approximately $100 \mathrm{yr}$, almost all calving dates of each cow were recorded and available. Although milk yields have been systematically observed since the beginning of the herd, only the best lactation record of each cow was kept and available for certain time periods. For other time periods records of multiple lactations were available for each cow. However, in an effort to minimize bias, only the best milk yield record of each cow was used. The use of all lactation records would add reporting bias to the analysis of DMY. The reader is cautioned to interpret results for DMY within the data space of the best lactation. For the analyses of DMY, if alive in 2009, only cows with ages above the average for the best production $(76 \mathrm{~m})$ were included.

For the analysis of AFC, only records of animals calving for the first time before 45 mo of age were included. Records of animals calving for the first time at older ages would tend to increase the residual variance as verified by the authors (results not shown) and would not be a useful representation of production animals. In this subpopulation, for some females, delaying exposure to breeding frequently occurred to maximize their growth rate. This tended to happen to some elite animals participating in livestock shows. As a consequence, observations of fertility as young females could not be recorded for those animals. The approach of Oseni et al. (2004) for establishing upper limits to traits to maximize the proportion of the genetic variation have been used in the determination of days open. For the analysis of CI, an upper limit of 30 mo has been established. Table 1 summarizes descriptive statistics on these 3 traits.

\section{Inbreeding}

Equal to the proportion of loci in an individual that carry alleles that are identical by descent from a common ancestor, inbreeding coefficients (Wright, 1931) were computed following Meuwissen and Luo (1992). Numbers of equivalent complete generations were calculated as the sum overall known ancestors of the term $(1 / 2)^{n}$, where $n$ is the number of generations separating the individual from each known ancestor (Gutiérrez and Goyache, 2005). Only cows with at least 4 equivalent generations of known pedigree were kept in all 
Table 1. Descriptive statistics of daily milk yield (DMY), age at first calving (AFC), and calving intervals (CI)

\begin{tabular}{lccccc}
\hline Trait & No. of records & Mean & SD & Minimum & Maximum \\
\hline DMY (kg) & 1,419 & 7.27 & 2.37 & 2.59 & 20.83 \\
AFC (mo) & 745 & 39.82 & 3.55 & 22.18 & 44.98 \\
CI (mo) & 4,420 & 16.31 & 4.53 & 8.94 & 30.13 \\
\hline
\end{tabular}

analyses. Individual increase in inbreeding coefficients, or inbreeding rates, were calculated according to the methodology described by González-Recio et al. (2007) and modified by Gutiérrez et al. (2009). Accordingly, individual increase in inbreeding coefficients $\left(\Delta F_{i}\right)$ were computed as

$$
\Delta F_{i}=1-\sqrt[t_{i}-1]{1-F_{i}},
$$

where $F_{i}$ is the inbreeding coefficient of individual $i$ and $t_{i}$ is the number of known equivalent generations for this individual.

This individual inbreeding rate becomes an alternative measure of inbreeding, which is adjusted for the depth of the known pedigree. This coefficient corrects the cumulative inbreeding coefficient $\left(F_{i}\right)$ for the number of generations recorded for an individual animal (González-Recio et al., 2007). Equivalent inbreeding coefficients were obtained through multiplying increase in inbreeding coefficients by the average number of equivalent generations on each trait, with the purpose of comparing values obtained from these 2 different approaches of measuring inbreeding.

Average coancestry between contemporary dams and sires was calculated to investigate mating policies adopted by the breeders. Dams were segregated according to their year of birth in time intervals of $3 \mathrm{yr}$. Average pairwise coancestry between each female $(i)$ born in each time interval and each respective male $(j)$ born in the same time interval or in the previous one, including all possible pairs, were calculated following Caballero and Toro $(2000,2002)$.

Inbreeding coefficients, coancestry, and equivalent complete generations were averaged by year of birth to plot the trend of the subpopulation with time. Individual inbreeding coefficients, average coancestry, number of founders, expected inbreeding by unbalancing of founders' contribution, number of equivalent complete generations, percentages of known ancestors by generation, and individual increase in inbreeding coefficients were computed using the ENDOG program (Gutiérrez and Goyache, 2005).

\section{Variance Components and Effects of Inbreeding}

Single-trait analyses were conducted using models where animal effects were fit as random effects. Each trait was analyzed twice. The fixed effect of inbreeding was first estimated as a covariate of individual inbreeding coefficients. Then, in a separate analysis for each trait, the fixed effect of inbreeding was estimated as a covariate of the individual increase in inbreeding coefficients.

Birth contemporary groups were created using year and farm at birth for the analyses of AFC and DMY. Year and farm at calving were used to form contemporary groups used in the DMY analyses. For DMY and AFC, the model was

$$
\mathbf{y}=\mathbf{X b}+\mathbf{Z a}+\mathbf{e},
$$

where $\mathbf{y}$ is a vector containing the phenotypic values for DMY or AFC; $\mathbf{b}$ is a vector of systematic fixed effects of contemporary groups and the regressions for the fixed covariates of season, age (only in the case of DMY), and individual inbreeding coefficient or individual increase in inbreeding; $\mathbf{a}$ is a vector of random animal additive genetic effects; $\mathbf{e}$ is a vector of random residual effects; and $\mathbf{X}$ and $\mathbf{Z}$ represent coefficient matrices relating records to systematic and animal effects, respectively. The random effects were assumed to be normally distributed with the expectation equal to zero and the following covariance structure:

$$
V\left[\begin{array}{l}
\mathbf{a} \\
\mathbf{e}
\end{array}\right]=\left[\begin{array}{cc}
\mathbf{A} \sigma_{a}^{2} & 0 \\
0 & \mathbf{I} \sigma_{e}^{2}
\end{array}\right],
$$

where $V$ is variance; $\sigma_{a}^{2}$ and $\sigma_{e}^{2}$ are the additive genetic and residual variances, respectively; $\mathbf{I}$ is an identity matrix of order equal to the number of cows; and $\mathbf{A}$ is Wright's numerator relationship matrix of the order equal to the number of animals in the pedigree.

Systematic variables used in the analysis of AFC included birth contemporary groups, linear and quadratic regression of AFC on individual inbreeding or on 
individual increase in inbreeding, and AFC Legendre polynomials regressions of order 3 on the day of birth within year (1 to 365), accounting for the seasonal effect. For DMY, systematic variables included birth contemporary groups, calving contemporary groups, linear regression of DMY on inbreeding or on individual increase in inbreeding, and DMY Legendre polynomials regressions of order 2 on age at calving.

In the case of CI the analysis was conducted by fitting a random regression model with Legendre polynomials of order 3 fitted for the fixed effect of age at calving and for both random animal and permanent environment effects. Year and farm of calving have composed contemporary groups for CI analysis. The model was

$$
\mathbf{y}=\mathbf{X b}+\mathbf{Q u}+\mathbf{Z} \mathbf{p e}+\mathbf{e},
$$

where $\mathbf{y}$ is a vector containing the observed CI; $\mathbf{b}$ is a vector of solutions for the contemporary groups and the fixed regressions, including individual inbreeding coefficient or individual increase in inbreeding (linear and quadratic regression, age at calving, and day of the year) both fitted using regression on their Legendre polynomials of order 3 ; $\mathbf{u}$ is a vector of random regressions for the animal additive genetic effect; $\mathbf{p e}$ is a vector of random regressions for the permanent environment effect; $\mathbf{X}$ is the incidence matrix relating records to the classification effects; and $\mathbf{Q}$ and $\mathbf{Z}$ are covariable matrices containing the orthogonal polynomials relating the animal genetic and permanent environment effects to age at calving. The random effects were assumed to be normally distributed with the expectation equal to zero and the following covariance structure:

$$
V\left[\begin{array}{c}
\mathbf{u} \\
\mathbf{p e} \\
\mathbf{e}
\end{array}\right]=\left[\begin{array}{ccc}
\mathbf{A} \sigma_{u}^{2} & 0 & 0 \\
0 & \mathbf{I}_{1} \sigma_{p e}^{2} & 0 \\
0 & 0 & \mathbf{I}_{2} \sigma_{e}^{2}
\end{array}\right],
$$

where $V$ is variance; $\sigma_{u}{ }^{2}, \sigma_{p e}{ }^{2}$, and $\sigma_{e}{ }^{2}$ are the additive genetic, permanent environment, and residual variances, respectively; $\mathbf{I}_{1}$ and $\mathbf{I}_{2}$ are identity matrices of order equal to the number of records and cows, respectively; and $\mathbf{A}$ is the Wright's numerator relationship matrix of the order equal to the number of animals in the pedigree.

All mixed model analyses were conducted by REML using Wombat (version 1.0; Meyer, 2007). At convergence, the lower bound sampling covariances among parameters estimated were used to approximate sampling errors of covariance components and genetic parameters. Also, curves for the fixed covariates fitted in the model were obtained from the generalized least squares solutions (Meyer, 2007). Differences between these solutions and each trait average were calculated as estimated effects according to the levels of the covariates. Raw means of the observations on each trait were also obtained according to the levels of the covariates. Differences between these raw means and each trait average have been calculated as average observed differences according to the levels of the covariates.

\section{RESULTS}

\section{Population Structure and Inbreeding}

Average actual inbreeding among the 9,055 inbred animals was $15.20 \%$. Considering the entire population, including inbred and noninbred animals, average inbreeding coefficient was $13.88 \%$. The average number of equivalent generations was 6.99 and the average increase in inbreeding by equivalent generation was $2.54 \%$, with an effective population size of 19.68. Among the females contributing data to the DMY analysis that were still alive in 2009, $100 \%$ were inbred, with a minimum inbreeding coefficient of $19.75 \%$, a maximum of $40.13 \%$, and an average of $26.42 \%$. The maximum inbreeding coefficient observed in the population was $49.45 \%$. The maximum inbreeding coefficient among the animals with data included in the analyses was $41.18 \%$.

Dispersion plots of inbreeding coefficients and increase in inbreeding equivalent coefficients are shown in Figures 1 and 2, respectively. Curves of the average inbreeding coefficients and average coancestry between sires and dams according to the year of birth are shown in Figure 3. A major reduction in the number of animals occurred in the period right before 1980, which can be seen in Figures 1 and 2. Inbreeding and coancestry averages markedly increased as a consequence of such reduction (Figure 3). During the most recent years, some animals with reduced inbreeding coefficients were born as a consequence of a recent change in the policy for mating decisions. It was decided to avoid breeding closely related cows and bulls. After 1997 average inbreeding percentages stopped increasing and even decreased after 2006. After 2000, intensive reproduction with use of IVF techniques allowed an increased number of animals in the herd (Figures 1 and 2) without introduction of animals from external herds. The aim of using IVF was to optimize the use of available semen from sires that descended from the same base population but had a low relationship to the available cows, thus reducing inbreeding.

Average inbreeding coefficients were usually similar to average coancestry between sires and dams available at each moment when observed along the generations. A comparison between the curves in Figure 3 shows 


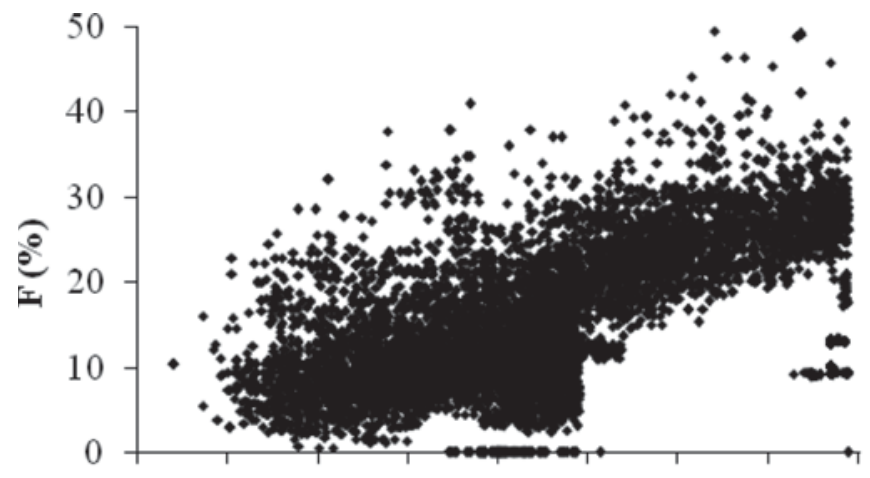

193019401950196019701980199020002010

Year of birth

Figure 1. Dispersion plot of percentage of inbreeding $[\mathrm{F}(\%)]$ according to dates of birth for animals with at least 4 equivalent generations of known pedigree data.

that mating policies did not account for inbreeding most of the time.

Average equivalent complete generations by year of birth are shown in Figure 4. The number of equivalent generations increased almost linearly because there was no introduction of animals with unknown pedigree information. The small decrease in the latest years (2007, 2008, and 2009) was attributed to the use of lowly related bulls via IFV. Animals with valid records were not exactly the same for the 3 analyzed traits. Accordingly, average numbers of equivalent complete generations composing the pedigrees of animals included in the analyses were 7.37 for DMY, 7.02 for AFC, and 4.15 for CI. Those average numbers of equivalent complete generations have been considered for the calculation of the equivalent inbreeding coefficients presented in Figures 5, 6, and 7 .

Pedigree completeness is reported in Figure 8. Parental generation 1 corresponds to parents, 2 corresponds to grandparents, and so on. About $90 \%$ of the pedigrees of the animals in the analysis of DMY contained information of at least 5 generations of ancestors.

\section{Variance Components and Effects of Inbreeding}

Variance components and heritability coefficients estimated for DMY, AFC, and CI in both approaches, with individual inbreeding coefficients or with individual increase in inbreeding coefficients, were very similar. Daily milk yield heritabilities were 0.27 , with a sampling error of 0.06, for both approaches. Age at first calving heritabilities were 0.37 for the approach using inbreeding coefficients, with a sampling error of 0.10 , and 0.38 for the approach using increase in inbreeding coefficients, also with a sampling error of 0.10 .
Estimates of genetic variance ratios for CI ranged from 0.07 , with a sampling error of 0.03 , corresponding to ages around $65 \mathrm{mo}$, to 0.14 , with a sampling error of 0.06 , corresponding to ages around 108 mo. Those results were also similar for both approaches, with inbreeding coefficients or with increase in inbreeding coefficients.

Observed differences from averages according to levels of inbreeding, and predicted effects of inbreeding on DMY, AFC, and CI, are shown in Figures 5, 6 , and 7, respectively. Solutions for the regressions of inbreeding on DMY, AFC, and CI were, respectively, $-0.0177,+0.0277$, and +0.0524 for the linear components and $-0.0003,-0.0020$, and +0.0024 for the quadratic components, representing the proportional effects of $1 \%$ increase on the inbreeding coefficients, or $-0.0134,+0.0289$, and +0.0378 for the linear components and $-0.0006,-0.0006$, and +0.0006 for the quadratic components, representing the proportional effects of $1 \%$ increase on the increase in inbreeding coefficients. Examination of Figure 5, regarding DMY, shows that predicted effects seemed not to follow the trends of the observed differences. Observed DMY differences increased with increased inbreeding whereas predicted effects were reduced. In the cases of AFC and CI, predicted and observed trends were in the same direction and magnitude.

\section{DISCUSSION}

The high average inbreeding levels found for this subpopulation were possibly reached for 2 reasons: 1 )

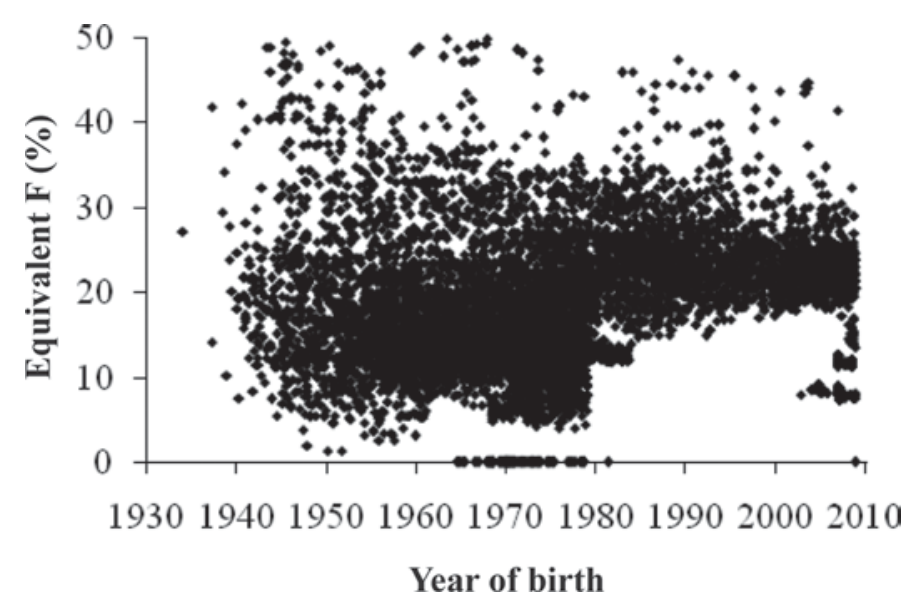

Figure 2. Dispersion plot of percentage of equivalent inbreeding [equivalent $\mathrm{F}(\%)$ ] according to dates of birth for animals with at least 4 equivalent generations of known pedigree data. Equivalent $\mathrm{F}(\%)$ was obtained by multiplying individual increase in inbreeding coefficients by 7.74 , which was the average equivalent number of generations on this pedigree. 


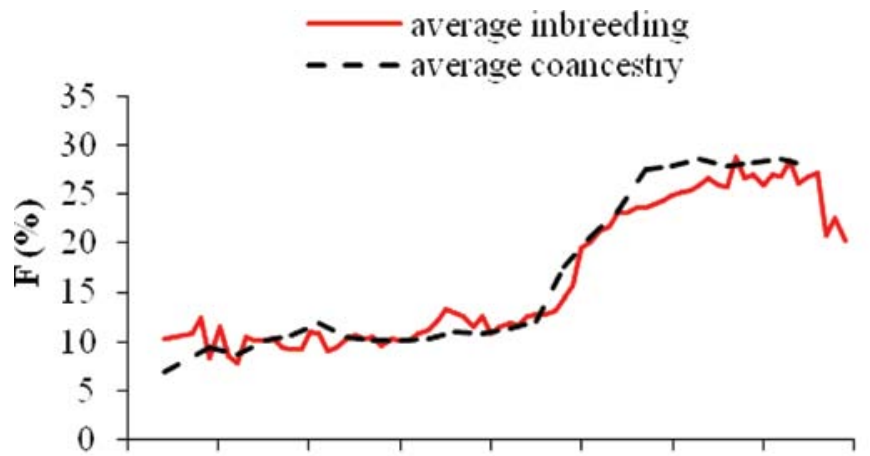

193019401950196019701980199020002010

\section{Year of birth}

Figure 3. Average inbreeding coefficients [percentage of inbreeding; $\mathrm{F}(\%)$ ] and average coancestry, according to year of birth, for animals with at least 4 equivalent generations of known pedigree data. Color version available in the online PDF.

the subpopulation was relatively small and closed (i.e., no external genetics have been used for a long period of time), and 2) mating policies generally did not avoid inbreeding, which was indicated by the similarity between average inbreeding coefficients and average coancestry between sires and dams along generations (Figure 3). Various other studies have been published reporting inbreeding values in small cattle populations. One example of very low inbreeding values was reported by Martínez et al. (2008) for 4 Colombian Creole cattle breeds, with average inbreeding coefficients that ranged from 0.18 to $1.22 \%$. Those Creole breeds, however, had been submitted to a program for conservation of genetic resources and the involved herds had been following a mating system designed to avoid inbreeding. In another study involving $55 \%$ of the Guzerat dairy animals registered with the Brazilian Association of Zebu Breeders (Uberaba, MG, Brazil) from 1938 to 1998, Faria et al. (2009) reported an average inbreeding of $1.75 \%$ for the Guzerat breed in Brazil, which was much less than what was observed in the present study.

Regarding highly inbred herds, Rumph et al. (2005) reported average inbreeding of $33.8 \%$ when analyzing a closed Hereford herd of 80 to 100 females in Montana. The largest inbreeding coefficient estimated in that beef cattle herd was 50.5\%. Carolino and Gama (2008) found individuals with inbreeding around $40 \%$ in the Alentejana cattle in Portugal. Some papers studying dairy cattle also reported maximum inbreeding coefficients with high magnitude. Peixoto et al. (2006) reported maximum values of $31 \%$ for Guzerat dairy cows in Brazil. Sewalem et al. (2006) found maximum values of $35.78,45.41$, and $44.71 \%$ when studying Jersey, Ayrshire, and Holstein herds, respectively, from Canada. The average values for the same herds were
3.60, 3.99, and 3.20, respectively. González-Recio et al. (2007) found animals with inbreeding coefficients up to $39 \%$ when studying Holstein cattle in Spain. In the same study, however, average inbreeding coefficients were only $3 \%$.

The inbreeding coefficients reported for the Guzerat herd in the present study were found, to the knowledge of the authors, to be the highest published to date for a dairy cattle population either in terms of maximum value for an animal (49.45\%) or in terms of average values $(26.42 \%$ average for the females providing milk yield records for the analysis that were still in the herd in 2009).

The heritability coefficient estimated for DMY, despite being obtained from only the best lactation of each animal instead of all lactations, was within the normal range found in the literature for this trait. Vercesi Filho et al. (2007) studied a zebu dairy population in Brazil (Mestiço Leiteiro Brasileiro) and estimated a heritability of 0.28 for milk yield. Gulisija et al. (2007) and Maiwashe et al. (2008) studied populations of Jersey cows, estimating heritability coefficients for 305-d milk yield of 0.34 and 0.26 , respectively.

Heritability coefficients estimated for AFC for zebu herds was found to vary among studies. Balieiro et al. (2003) estimated a coefficient of 0.18 for Gyr dairy cattle. Paneto et al. (2008) have found a heritability of 0.20 for AFC in a subset of the same Guzerat herd used in the present study, but with a less deep pedigree file available for that study and with no restriction for the maximum age to be considered as first calving. Facó et al. (2008) studied dairy herds comprising crosses between the Gyr and Holstein breeds, finding a heritability of 0.33 for AFC. Vercesi Filho et al. (2007) applied a restriction to the maximum age to be considered as

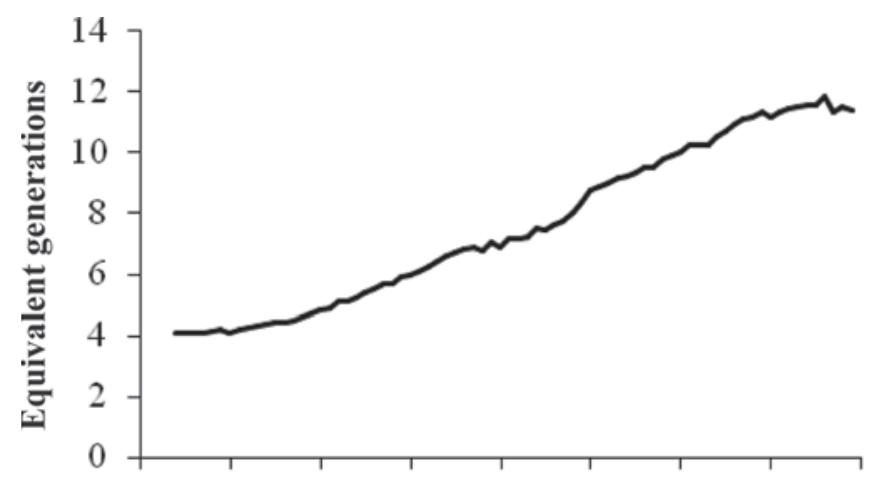

193019401950196019701980199020002010

\section{Year of birth}

Figure 4. Historical averages of equivalent complete generations according to dates of birth for animals with at least 4 equivalent generations of known pedigree data. 


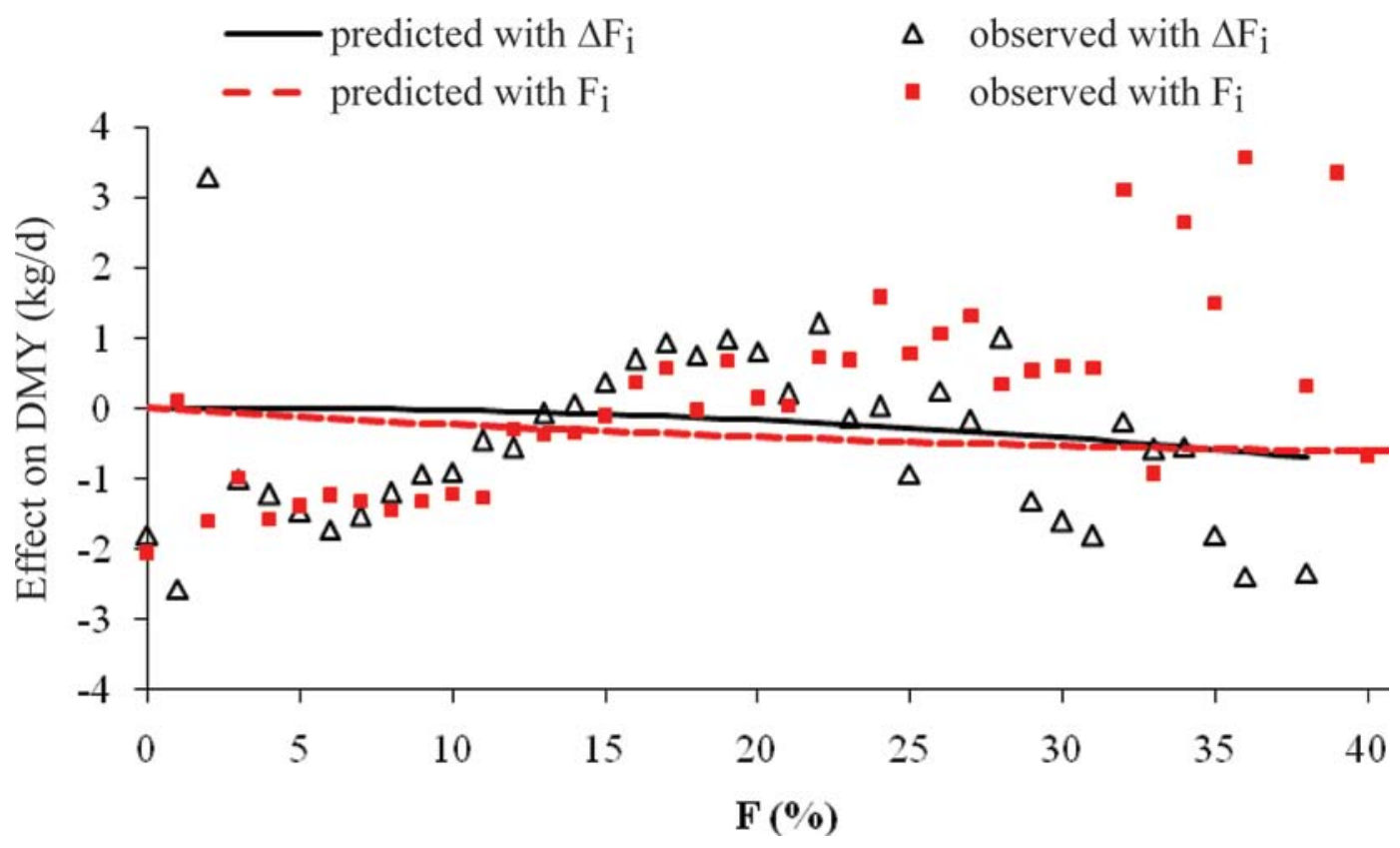

Figure 5. Observed differences from average daily milk yield (DMY) according to inbreeding measured with regular inbreeding coefficients $\left(F_{i}\right)$ or with increase in inbreeding coefficients $\left(\Delta F_{i}\right)$. Lines represent the predicted effects of these 2 measures of inbreeding obtained from the generalized least squares solutions on DMY. F $(\%)=$ percentage of inbreeding. Color version available in the online PDF.

first calving and found a heritability coefficient of 0.48 for this trait. One explanation for the high values found in the present study or in the study of Vercesi Filho et al. (2007) can be the restriction for the maximum age allowed to consider a record as first calving. Another possible explanation for these high heritability values was that all the animals were under the same kind of management because they were in just 1 herd,

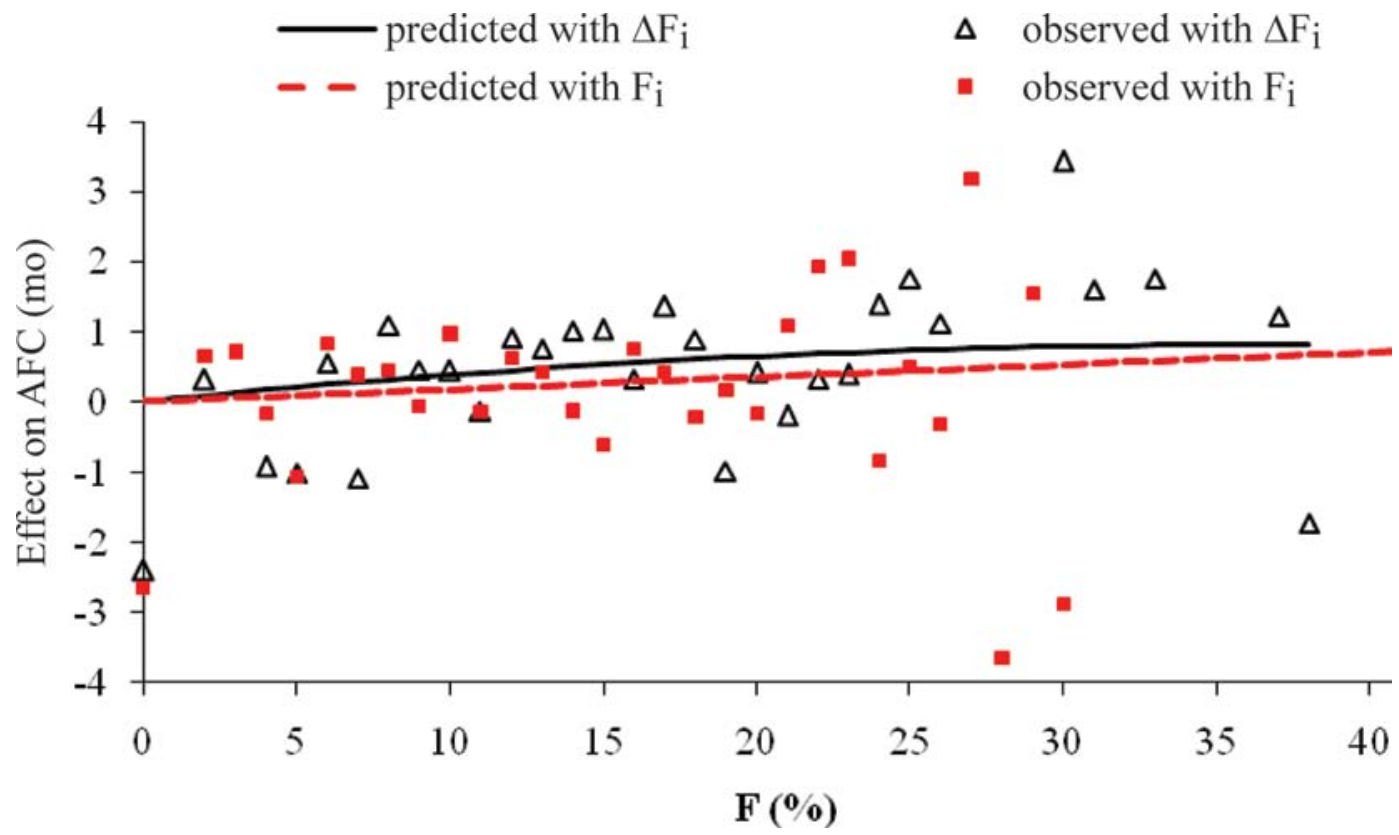

Figure 6. Observed differences from average ages at first calving (AFC) according to inbreeding measured with regular inbreeding coefficients $\left(F_{i}\right)$ or with increase in inbreeding coefficients $\left(\Delta F_{i}\right)$. Lines represent the predicted effects of these 2 measures of inbreeding obtained from the generalized least squares solutions on AFC. F $(\%)=$ percentage of inbreeding. Color version available in the online PDF. 


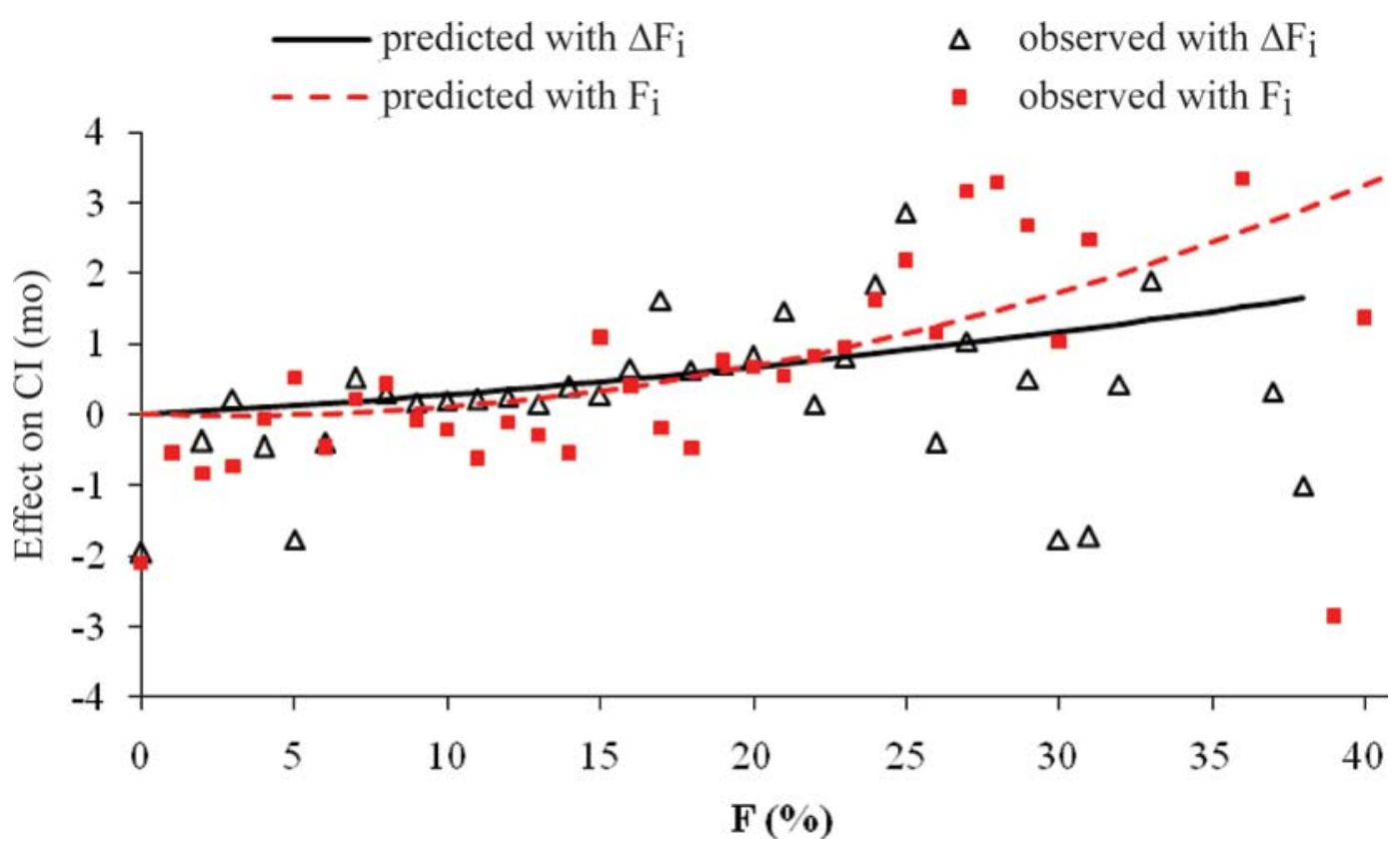

Figure 7. Observed differences from average calving intervals (CI) according to inbreeding measured with regular inbreeding coefficients $\left(F_{i}\right)$ or with increase in inbreeding coefficients $\left(\Delta F_{i}\right)$. Lines represent the predicted effects of these 2 measures of inbreeding obtained from the generalized least squares solutions on CI. F $(\%)=$ percentage of inbreeding. Color version available in the online PDF.

with a very complete and deep pedigree and very high genetic relationships among all animals involved. This would tend to reduce the residual variance and allow for a more effective resolution of the additive genetic effects.

The additive genetic variance component for CI represented about $10 \%$ of the phenotypic variation on this trait. Because CI was analyzed as a longitudinal trait, this proportion varied with age of calving. Most studies on CI estimate the proportion of the genetic additive variance component to be less than or around $10 \%$ (Balieiro et al., 2003; Peña et al., 2008; Yagüe et al., 2009).

Because individual increase in inbreeding coefficients is essentially the same as inbreeding but with a correction for the number of equivalent known generations for each animal, and because both approaches with inbreeding or increase in inbreeding have resulted in similar heritabilities for the studied traits, it would be advisable to use increase in inbreeding coefficients in future analyses because it accounts for more information on the animals (number of equivalent generations available in the pedigree). Cassell et al. (2003) also tested 2 different models, including the regular inbreeding coefficients or an alternative approach for the calculation of inbreeding, and found no difference between methods regarding the estimates of heritabilities, similar to what was observed in the present study. Smith et al. (1998) and Cassell et al. (2003) had found that inbreeding de- pression could be better captured when pedigree information was more complete, indicating the importance of the information of pedigree completeness. Another reason to choose increase in inbreeding coefficients is that regular inbreeding coefficients generally grow with time and may be confounded with the effect accounting for the time such as the contemporary groups, whereas

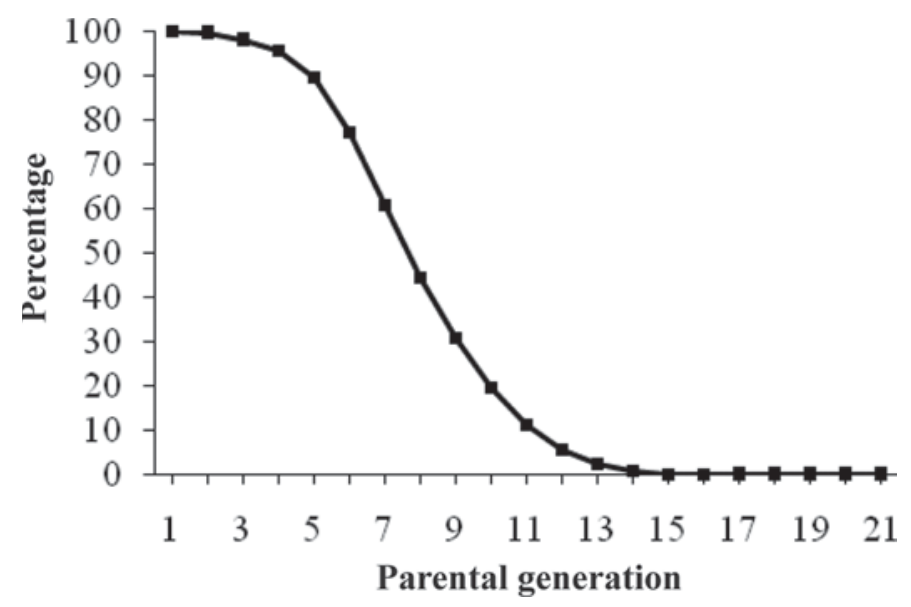

Figure 8. Completeness level of the pedigrees for the 1,419 animals included in the daily milk yield analysis, assessed by means of percentage of ancestors known per parental generation, where parental generation 1 corresponds to parents, 2 corresponds to grandparents, and so on. 
individual increases in inbreeding do not grow with time (Figures 1 and 2).

An inspection of the curves in Figure 5, specifically those related to the analyses using inbreeding coefficients, shows that increased inbreeding was associated with increased observed mean DMY, whereas the predicted effect of increased inbreeding was a reduced average DMY in the same population. Use of inbred mating and simultaneous selection on milk yield would have tended to result in the genetically superior animals, in terms of milk yield, to be among the most inbred animals. This could potentially be attributed to the fact that individuals surviving to high levels of inbreeding would be free from most deleterious alleles. Also, inbreeding depression tends to affect traits related to fitness such as reproductive traits. Still, the examination of the curves related to the approach with individual increase in inbreeding illustrates that the same trend for the observed mean DMY also existed (Figure 5), but only until a certain level of inbreeding, corresponding to values around 20\%. Above this level, observed mean DMY did not increase with additional inbreeding measured through individual increase in inbreeding.

Despite the cited positive relationship between observed DMY and inbreeding, when the effect of selection was excluded as shown with the predicted lines in Figures 5, 6, and 7, the general effect of inbreeding on the herd was to diminish DMY and to increase ages at first calving and CI.

Another fact to be remembered is that most animals were inbred in this population. Thus, the more consistent comparison being made in this study was between animals less inbred and more inbred. Until 1980 there was a wide variation on the inbreeding coefficients. For some periods, however, less inbreeding corresponded to inbreeding coefficients around $20 \%$. Recently, wider variation has taken place once more.

Even if the directions of the effects of inbreeding were the same for both approaches, the shapes of the curves predicted were different from each other (Figure 5). For example, mating between half-sibs with no previous inbreeding (cumulative inbreeding $=12.5 \%$ ) would lead to reductions of 84.61 or $15.25 \mathrm{~kg}$ for $305-\mathrm{d}$ lactations according to the estimates from the models with inbreeding coefficients or with increase in inbreeding coefficients, respectively. Mating between full-sibs would result in inbreeding depression of 144.99 or 83.77 $\mathrm{kg}$, respectively, for the same trait. Both models would predict similar inbreeding depression for milk yield in the case of animals with inbreeding coefficients around $34 \%$.
Hudson and Van Vleck (1984), Smith et al. (1998), and Thompson et al. (2000), using data on Holstein cows, found much bigger values of inbreeding depression on milk yield than the present study. Considering mating between half-sibs, for example, their estimates ranged from 345 to $480 \mathrm{~kg}$ expected reduction in the 305-d yield. Mc Parland et al. (2007), studying Irish Holstein-Friesians, found an inbreeding depression estimate that included linear and quadratic terms that would result in a reduction of $62 \mathrm{~kg}$ on 305-d lactations for $12.5 \%$ inbred animals, which was closer to what was found in the present study with the Guzerats. Studying Jersey cows, Gulisija et al. (2007) found that a nonlinear regression would result in a reduction of $380 \mathrm{~kg}$ in the 305 -d lactations for $12.5 \%$ inbred cows. In the study of Maiwashe et al. (2008), for the same class of inbreeding, a reduction around $170 \mathrm{~kg}$ would be expected.

Potentially, in the first approach, with inbreeding coefficients, the increase of inbreeding coefficients would be associated with additional generations of known pedigree data, resulting in higher values of inbreeding for the most recent years. This would coincidentally correspond to more selected contemporary groups. In the second approach, the equivalent inbreeding values are corrected for the number of equivalent generations. Thus, theoretically, they would more accurately model the increase in homozygosis expected from inbreeding. Some assumptions from the examination of Figure 5 and the inbreeding depression on DMY would be 1) the reduction on the frequencies of deleterious alleles related to DMY occurred in this population through selection on this trait, and 2) the model with the simple inbreeding coefficients could be overestimating the effect of inbreeding depression for levels under 34\%, which would include most of the animals in the present analysis.

Ages at first calving and CI have been affected by inbreeding depression in the same direction but with different shapes for each statistical model. For example, mating between half-sibs would result in delays of 6.7 or $14.0 \mathrm{~d}$ in the AFC and increases of 6.1 or $11.0 \mathrm{~d}$ in the CI, according to the models with inbreeding coefficients or with individual increase in inbreeding coefficients, respectively. Thus, inbreeding depression may have been underestimated with the first model for $\mathrm{AFC}$ and $\mathrm{CI}$ in the case of breeding between half-sibs. Mating between full-sibs would result in delays of 13.4 or $22.2 \mathrm{~d}$ in the AFC and increases of 34.7 or $27.4 \mathrm{~d}$ in the CI for one model or the other, according to the models with inbreeding coefficients or with individual increase in inbreeding coefficients, respectively. Thus, in the case of high levels of inbreeding, the model with 
inbreeding coefficients could be overestimating inbreeding depression for CI, but the opposite would be happening for AFC.

Hudson and Van Vleck (1984) found an expected increase of $2.0 \mathrm{~d}$ in the CI of females with inbreeding coefficients around 12.5\%. Smith et al. (1998) estimated an average delay of $5 \mathrm{~d}$ in the ages at first calving from $12.5 \%$ inbreeding. In the study of Mc Parland et al. (2007), mating between half-sibs would result, on average, in a delay of $2.5 \mathrm{~d}$ in the AFC and in an increase of $8.8 \mathrm{~d}$ in the CI. For Carolino and Gama (2008), the linear effect of inbreeding on CI of the Alentejana cattle was $0.263 \mathrm{~d} / 1 \%$ inbreeding, which would result in 3.3 d for cows with $12.5 \%$ inbreeding. González-Recio et al. (2007) found a linear effect of inbreeding decreasing fertility. However, they analyzed pregnancy rate as compared with CI.

Finally, inbreeding depression on CI seemed to be overestimated for animals with high levels of inbreeding (above 25\%) in the model with inbreeding coefficients. One hypothesis is that the animals with high inbreeding levels would be the same animals highly selected for milk yield. The correlated response to selection for milk yield may have also resulted in the overestimation of inbreeding depression for fertility traits (Lucy, 2001; Hare et al., 2006).

\section{CONCLUSIONS}

The general effect of inbreeding on the herd was to diminish DMY and to increase AFC and CI. However, some cows with the highest milk yield were among the highly inbred animals in this population. Individual increase in inbreeding used as a covariate in the statistical models accounted for the inbreeding depression while avoiding potential overestimation of this effect on more recent generations attributed to increased numbers of known generations.

\section{ACKNOWLEDGMENTS}

The authors acknowledge CAPES (Coordenação de Aperfeiçoamento de Pessoal de Nível Superior, Brasília, DF, Brazil), a foundation affiliated with the Ministry of Education of Brazil, and FAPEMIG (Minas Gerais State Foundation for Research Development, Belo Horizonte, MG, Brazil) for the financial support, and also the Guzerá JA breeders for kindly providing the unique herd data used in the present study (Guzerá JA is a trademark for an elite dairy Guzerat subpopulation, started in Brazil by João de Abreu Júnior in 1895).

\section{REFERENCES}

Balieiro, E. S., J. C. C. Pereira, R. S. Verneque, J. C. C. Balieiro, and J. Valente. 2003. Estimates of heritability and genetic relationship between some reproductive traits and milk yield in Gyr cattle. Arq. Bras. Med. Vet. Zootec. 55:85-91.

Caballero, A., and M. A. Toro. 2000. Interrelations between effective population size and other pedigree tools for the management of conserved populations. Genet. Res. Camb. 75:331-343.

Caballero, A., and M. A. Toro. 2002. Analysis of genetic diversity for the management of conserved subdivided populations. Conserv. Genet. 3:289-299.

Carolino, N., and L. T. Gama. 2008. Inbreeding depression on beef cattle traits: Estimates, linearity of effects and heterogeneity among sire-families. Genet. Sel. Evol. 40:511-527.

Cassell, B. G., V. Adamec, and R. E. Pearson. 2003. Effect of incomplete pedigrees on estimates of inbreeding and inbreeding depression for days to first service and summit milk yield in Holsteins and Jerseys. J. Dairy Sci. 86:2967-2976.

Facó, O., R. N. B. Lôbo, R. Martins Filho, G. A. Martins, S. M. P. Oliveira, and D. M. M. R. Azevêdo. 2008. Additive and non-additive genetic effects on productive and reproductive traits in Holstein $\times$ Gyr crosbred cows. R. Bras. Zootec. 37:48-53.

Falconer, D. S. 1981. Introduction to Quantitative Genetics. 2nd ed. Longman House, Harlow, UK.

Faria, F. J. C., A. E. Vercesi Filho, F. E. Madalena, and L. A. Josakian. 2009. Pedigree analysis in the Brazilian Zebu breeds. J. Anim. Breed. Genet. 126:148-153.

González-Recio, O., E. López de Maturana, and J. P. Gutiérrez. 2007. Inbreeding depression on female fertility and calving ease in Spanish dairy cattle. J. Dairy Sci. 90:5744-5752.

Gulisija, D., D. Gianola, and K. A. Weigel. 2007. Nonparametric analysis of inbreeding on production in Jersey cows. J. Dairy Sci. 90:493-500.

Gutiérrez, J. P., I. Cervantes, and F. Goyache. 2009. Improving the estimation of realized effective population sizes in farm animals. J. Anim. Breed. Genet. 126:327-332.

Gutiérrez, J. P., and F. Goyache. 2005. A note on ENDOG: A computer program for analyzing pedigree information. J. Anim. Breed. Genet. 122:172-176.

Hare, E., H. D. Norman, and J. R. Wright. 2006. Trends in calving ages and calving intervals for dairy cattle breeds in the United States. J. Dairy Sci. 89:365-370.

Hudson, G. F. S., and L. D. Van Vleck. 1984. Effects of inbreeding on milk and fat production, stayability, and calving interval of registered Ayrshire cattle in Northeastern United States. J. Dairy Sci. 67:171-179.

Lucy, M. C. 2001. Reproductive loss in high-producing dairy cattle: Where will it end? J. Dairy Sci. 84:1277-1293.

Maiwashe, A., K. A. Nephawe, and H. E. Theron. 2008. Estimates of genetic parameters and effect in inbreeding on milk yield and composition in South African Jersey cows. S. Afr. J. Anim. Sci. $38: 119-125$.

Martínez, R. A., D. García, J. L. Gallego, G. Onofre, J. Pérez, and J. Cañón. 2008. Genetic variability in Colombian Creole cattle populations estimated by pedigree information. J. Anim. Sci. $86: 545-552$.

Mc Parland, S., J. F. Kearney, M. Rath, and D. P. Berry. 2007. Inbreeding effects on milk production, calving performance, fertility, and conformation in Irish Holstein-Friesians. J. Dairy Sci. 90:4411-4419

Meuwissen, T., and Z. Luo. 1992. Computing inbreeding coefficients in large populations. Genet. Sel. Evol. 24:305-313.

Meyer, K. 2007. WOMBAT-A tool for mixed model analyses in quantitative genetics by restricted maximum likelihood (REML) . J. Zhejiang Univ. Sci. B 8:815-821.

Oseni, S., S. Tsuruta, I. Misztal, and R. Rekaya. 2004. Genetic parameters for days open and pregnancy rates in US Holsteins using different editing criteria. J. Dairy Sci. 87:4327-4333.

Paneto, J. C. C., J. B. S. Ferraz, J. C. C. Balieiro, J. F. F. Bittar, M B. D. Ferreira, M. B. Leite, G. K. F. Merigue, and F. V. Meirelles. 
2008. Bos indicus or Bos taurus mitochondrial DNA - Comparison of productive and reproductive breeding values in a Guzerat dairy herd. Genet. Mol. Res. 7:592-602.

Peixoto, M. G. C. D., R. S. Verneque, R. L. Teodoro, V. M. Penna and M. L. Martinez. 2006. Genetic trend for milk yield in Guzerat herds participating in progeny testing and MOET nucleus schemes. Genet. Mol. Res. 5:454-465.

Peña, R. L., D. G. Iglesias, D. G. Peña, J. L. E. Villavicencio, A. P. Espinosa, and R. N. Domínguez. 2008. Components of (co)variance for reproductive traits and their genetic relationship to weaning weight in Cuban zebu cattle. Téc. Pecu. Méx. 46:225-234.

Rumph, J. M., D. D. Kress, K. C. Davis, D. C. Anderson, H. C. Van Wagoner, and D. L. Boss. 2005. Influence in incorrect estimates of inbreeding on the genetic analysis of mature cow weights in a population of inbred Hereford cattle. Pages 121-124 in Proc. Western Section, American Society of Animal Science, Las Cruces, NM. American Society of Animal Science, Champaign, IL.

Sewalem, A., G. S. Kistemaker, F. Miglior, and B. J. Van Doormaal 2006. Analysis of inbreeding and its relationship with functional longevity in Canadian dairy cattle. J. Dairy Sci. 89:2210-2216.
Smith, L. A., B. G. Cassel, and R. E. Pearson. 1998. The effects of inbreeding on the lifetime performance of dairy cattle. J. Dairy Sci. 81:2729-2737.

Thompson, J. R., R. W. Everett, and N. L. Hammerschmidt. 2000 Effects of inbreeding on production and survival in Holsteins. J. Dairy Sci. 83:1856-1864.

Van Wyk, J. B., M. D. Fair, and S. W. P. Cloete. 2009. Case study: The effect of inbreeding on the production and reproduction trait in the Elsenburg Dormer sheep stud. Livest. Sci. 120:218-224.

Vercesi Filho, A. E., F. E. Madalena, L. G. Albuquerque, A. F. Freitas, L. E. Borges, J. J. Ferreira, R. L. Teodoro, and F. J. C. Faria. 2007. Genetic parameters between milk traits and age at first calving in crosbreed dairy cattle (Bos taurus $\times$ Bos indicus). Arq. Bras. Med. Vet. Zootec. 59:983-990.

Wright, S. 1931. Evolution in Mendelian populations. Genetics 16:97159.

Yagüe, G., F. Goyache, J. Becerra, C. Moreno, L. Sánchez, and J. Altarriba. 2009. Bayesian estimates of genetic parameters for preconception traits, gestation length and calving interval in beef cattle. Anim. Reprod. Sci. 114:72-80. 